\title{
Nematicidal Activity of Cry1Ea11 from Bacillus thuringiensis BRC-XQ12 Against the Pine Wood Nematode (Bursaphelenchus xylophilus)
}

\author{
Tianpei Huang, Qunxin Lin, Xiaoli Qian, Ying Zheng, Junmin Yao, Huachuan Wu, Mengmeng Li, Xin Jin, Xiaohong Pan, \\ Lingling Zhang, and Xiong Guan ${ }^{\dagger}$
}

All authors: State Key Laboratory of Ecological Pest Control for Fujian and Taiwan Crops \& Key Laboratory of Biopesticide and Chemical Biology (Ministry of Education), College of Life Sciences, Fujian Agriculture and Forestry University, and first, fifth, sixth, seventh, eighth, ninth, tenth, and eleventh authors: Fujian-Taiwan Joint Center for Ecological Control of Crop Pests, Fuzhou, Fujian, People's Republic of China, 350002.

Accepted for publication 8 September 2017.

\begin{abstract}
The nematicidal activity of 92 Bacillus thuringiensis strains against the pine wood nematode Bursaphelenchus xylophilus, one of the world's top 10 plant-parasitic nematodes, was determined. The insecticidal crystal proteins (ICPs) from Bacillus thuringiensis BRC-XQ12 were the most toxic to Bursaphelenchus xylophilus, with a lethal concentration $50\left(\mathrm{LC}_{50}\right)$ of $32.13 \mu \mathrm{g} / \mathrm{ml}$. Because the ICPs expressed by Bacillus thuringiensis BRC-XQ12 were closest to Cry1Ea6 and B. thuringiensis BRC-XQ12 contained four kinds of $c r y l$ subgenes (crylAa, crylCb, crylEa, and crylla), CrylEa was most likely to be the key active component against the nematode. The 3,516-bp crylEa11 gene from BRC-XQ12, as designated by the B. thuringiensis $\delta$-endotoxin nomenclature committee, was expressed in Escherichia coli. Purified Cry1Ea11 showed an $\mathrm{LC}_{50}$ of 32.53 and $23.23 \mu \mathrm{g} / \mathrm{ml}$ at 24 and $48 \mathrm{~h}$,

with corresponding virulence equations of $Y=32.15 X+1.38\left(R^{2}=0.9951\right)$ and $Y=34.29 X+3.16\left(R^{2}=0.9792\right)$, respectively. In order to detect the pathway of B. thuringiensis Cry1Ea11 into Bursaphelenchus xylophilus, the nematode was fed with NHS-rhodamine-labeled GST-Cry1Ea11. The results of confocal laser-scanning microscopy showed that the $159-\mathrm{kDa}$ GST-Cry1Ea11 could be detected in the stylet and the esophageal lumen of the pine wood nematode, indicating that GST-Cry1Ea11 could enter into the nematode through the stylet. As far as we know, no Cry 1 proteins have been shown to have activity against plant-parasitic nematodes before. These results demonstrate that Cry1Ea11 is a promising nematicidal protein for controlling pine wilt disease rendered by $B$. xylophilus, further dramatically broadening the spectrum of Bacillus thuringiensis ICPs.
\end{abstract}

Plant-parasitic nematodes are important crop pathogens, causing yearly losses of approximately $\$ 10$ billion in the United States and $\$ 78$ to 125 billion worldwide (Batish et al. 2008; Chitwood 2003). Thus far, more than 4,100 species of plant-parasitic nematodes have been described (Jones et al. 2013). Of these nematodes, Bursaphelenchus xylophilus (Steiner \& Buhrer) Nickle (pine wood nematode [PWN]) was one of the world's top 10 plant-parasitic nematodes and a major invasive organism causing pine wilt disease (PWD), leading to significant losses of $2 \times 10^{6} \mathrm{~m}^{3}$ of timber under some environmental conditions (Jones et al. 2013; Zhao et al. 2014).

B. xylophilus is unique in that it can live on living trees and the fungi colonizing dead or dying trees in its life cycle (Kikuchi et al. 2011). It has propagative and reproduction forms in its life cycle (Aikawa et al. 2003). With pine wilting or death, the second-instar larvae will mature to third-instar larvae, passing the winters with their vector beetle Monochamus alternatus (Japanese pine sawyer) in the xylem (Akbulut and Stamps 2012). Then, the fourth-instar larvae move with M. alternatus to healthy pine (Jung et al. 2010; Zhao et al. 2014). Because PWD can cause rapid death in a variety of pine species and B. xylophilus has plant and fungal feeding styles, prevention of PWD is extremely difficult (Jones et al. 2013). Thus, many countries pay a high level of attention to its control (Yang et al. 2014).

Because the pathogenesis of PWD has not been fully clarified, the control of the plant-parasitic nematode is largely dependent on chemical nematicides such as fumigants; however, most of them have been banned by the European Commission (D'Addabbo et al. 2014).

†Corresponding author: X. Guan; E-mail: guanxfafu@126.com

*The $\boldsymbol{e}$-Xtra logo stands for "electronic extra" and indicates that six supplementary figures and three supplementary tables are published online.

(C) 2018 The American Phytopathological Society
Additionally, extensive use of chemical pesticides has caused the insurmountable " 3 R" problem. Therefore, given the current shortcomings of $B$. xylophilus control, it is necessary to develop new strategies such as biological control for the sustainable control of B. xylophilus (Chu et al. 2015; Kim et al. 2008; Seo et al. 2010).

Bacillus thuringiensis is a well-known biopesticide and contains a variety of biologically active substances such as insecticidal crystal proteins (ICPs) (Bravo et al. 2011; Dai et al. 2016; Deng et al. 2014; Sanahuja et al. 2011). B. thuringiensis ICPs are active against members of the orders Hymenoptera, Lepidoptera, Coleoptera, and Diptera; plus protozoa, nematodes, platyhelminths, schistosomiasis, malaria parasites, mites, and others (Bravo et al. 2011; Kotze et al. 2005; Sanahuja et al. 2011; Wei et al. 2003). However, the nature of most of the components active against nematodes remains unknown (Wang et al. 2014; Yu et al. 2015). This study attempts to screen $B$. thuringiensis strains active against the PWN Bursaphelenchus xylophilus and to further identify the active component using mass spectrometry (MS), polymerase chain reaction restriction fragment length polymorphism (PCR-RFLP), heterologous expression, and bioassays. Herein, we first showed that Cry1 was active against the plant-parasitic nematode $B$. xylophilus. The nematode was further fed with NHS-rhodamine-labeled glutathione- $S$ transferase (GST)-Cry1Ea11 and observed with confocal laserscanning microscopy (CLSM) to make sure the nematode could take up such a large protein and to detect the pathway of Bacillus thuringiensis Cry1Ea11 into Bursaphelenchus xylophilus. This work may lay a foundation for the effective control of B. xylophiluslike plant-parasitic nematodes.

\section{MATERIALS AND METHODS}

Bacterial strains and nematode. Escherichia coli JM109 and BL21 (DE3) and expression plasmid pGEX-KG were stocked 
in the State Key Laboratory of Ecological Pest Control for Fujian and Taiwan Crops, China. B. xylophilus was reared by the same lab. Because B. xylophilus is classified as an internal and external important quarantine object, it is impossible for foreign counterparts to share this experimental material. Bacillus thuringiensis strains used in this study are listed in the Supplementary Table S1.

Media and reagents. Luria-Bertani (LB), potato dextrose agar (PDA), and peptone-medium (PM) $(0.2 \%$ yeast extract, $1 \%$ glucose, $1 \%$ tryptone, $0.1 \% \mathrm{KH}_{2} \mathrm{PO}_{4}, 0.1 \% \mathrm{~K}_{2} \mathrm{HPO}_{4}, 0.002 \%$ $\mathrm{MgSO}_{4} \cdot 7 \mathrm{H}_{2} \mathrm{O}, 0.002 \% \mathrm{FeSO}_{4} \cdot 7 \mathrm{H}_{2} \mathrm{O}, 0.002 \% \mathrm{ZnSO}_{4} \bullet 7 \mathrm{H}_{2} \mathrm{O}$, and $0.002 \% \mathrm{MnSO}_{4} \cdot 7 \mathrm{H}_{2} \mathrm{O}[\mathrm{pH} 7.2]$ ) were used in this study. Taqase, PCR product recovery kits, T4 DNA ligase, restriction enzymes, and pMD18-T vector were from TaKaRa Co., Ltd.. Vent DNA polymerase was from New England Biolabs. Proteinase K was from Boehringer Mannheim Co, Ltd.. Lysozyme was from Shanghai Bioasia Co, Ltd.. Other reagents were analytical pure products purchased in China.

Culturing and isolation of Bursaphelenchus xylophilus. Bursaphelenchus xylophilus was isolated from susceptible Pinus thunbergii using the Baermann funnel method (Beane and Hobbs 1983). Briefly, Botrytis cinerea was inoculated on a PDA plate at $25^{\circ} \mathrm{C}$. When the whole plate was covered with the mycelia of $B$. cinerea, the nematodes were inoculated onto the plates. After 7 days, the medium containing the nematodes was put in a Baermann funnel and rinsed with sterile Milli-Q water to wash out the nematodes. The nematodes were collected via centrifugation at $1,000 \mathrm{rpm}$, disinfected with $0.1 \%$ streptomycin sulfate, and concentrated to $10 / \mu l$ of suspension.

Screening of Bacillus thuringiensis strains active against Bursaphelenchus xylophilus. Bacillus thuringiensis was incubated in $50 \mathrm{ml}$ of $\mathrm{LB}$ at $200 \mathrm{rpm}$ and $30^{\circ} \mathrm{C}$ for 3 days. Then, the fermentation broth containing ICPs was diluted to 1 (optical density at $600 \mathrm{~nm}$ ) with sterile Milli-Q water. The activity was determined by a dipping method. Briefly, $100 \mu \mathrm{l}$ of the above fermentation broth was transferred into each well of a 96-well plate. LB broth was used as a negative control. Then, 100 nematodes suspended in $100 \mu \mathrm{l}$ of sterile Milli-Q water were added to each well. They were mixed well and cultured at $25^{\circ} \mathrm{C}$ under dark and wet conditions. After $48 \mathrm{~h}$, the mortality was determined with a microscope. If the nematodes had $\mathrm{C} / \mathrm{J}$-like shapes or did not move after repeated stimulation with $50 \mu \mathrm{l}$ of water, they were recorded as dead. If they were wavy, spiral curled, or "S" shaped, they were recorded as alive. The mortality and corrected mortality of Bursaphelenchus xylophilus were calculated. The mortality of the nematodes suspended in $100 \mu \mathrm{l}$ of sterile Milli-Q water was used as the control group mortality. Corrected mortality $(\%)=($ treatment group mortality - control group mortality $) /$ $(100-$ control group mortality $) \times 100$. Each treatment was repeated three times. The fermentation broths of the Bacillus thuringiensis strains with $>80 \%$ corrected mortality were rescreened by diluting 30 times. The bioassay was performed as above.

Preparation of $\boldsymbol{B}$. thuringiensis ICPs. Overnight culture (1\%) of the $B$. thuringiensis strains was transferred to PM media and cultivated at $37^{\circ} \mathrm{C}$ with shaking at $220 \mathrm{rpm}$ until ICPs formed. Then, the fermentation broth was centrifuged at $10,000 \mathrm{rpm}$ and $4^{\circ} \mathrm{C}$ for $10 \mathrm{~min}$. To wash the pellets, $1 \mathrm{M} \mathrm{NaCl}$ solution and sterile Milli-Q water were applied three times. Solution $\mathrm{I}\left(50 \mathrm{mM} \mathrm{Na}_{2} \mathrm{CO}_{3} / \mathrm{HCl}\right.$ and $10 \mathrm{mM}$ dithiothreitol [DTT], $\mathrm{pH}$ 9.5) was used to dissolve the precipitate. After centrifugation, 1:3 diluted acetic acid was gradually added to the supernatants until the $\mathrm{pH}$ reached 4.6 to 4.8 , and the precipitate was left overnight. After centrifugation, sterile Milli-Q water was used to wash the precipitate three times. After centrifugation, a $0.01 \mathrm{M} \mathrm{NaOH}$ solution was used to dissolve the precipitate. After centrifugation, the supernatants were loaded into dialysis bags with $0.01 \mathrm{M}$ phosphate-buffered saline ( $\mathrm{pH}$ 7.4), stirring overnight at $4^{\circ} \mathrm{C}$. After centrifugation, the concentration of the supernatants was confirmed by the Bradford method (Bradford 1976).

Bioassay of B. thuringiensis ICPs on Bursaphelenchus xylophilus. Nematodes $(n=100)$ suspended in $100 \mu$ l of sterile Milli-Q water were added to each well of a 96-well plate. The above ICPs were diluted in a twofold ratio. The dilutions $(100 \mu \mathrm{l})$ were added to the above wells, with $0.01 \mathrm{MNaOH}$ as a negative control. The percentage of live nematodes was calculated under a microscope every $12 \mathrm{~h}$, as described above.

Effect of Bacillus thuringiensis ICPs on the proliferation of Bursaphelenchus xylophilus. Alternaria Nees was inoculated in PDA media at $25^{\circ} \mathrm{C}$ for 5 days. In $1 \mathrm{ml}$ of sterile Milli-Q water, 5,000 nematodes were mixed with 19 and $43.5 \mu \mathrm{g}$ of ICPs from BRC-ZY3 and BRC-XQ12, respectively. Sterile Milli-Q water was used as a negative control. After 12, 24, 36, and 48 h, every 200 nematodes isolated by the Baermann funnel method were put onto a PDA plate and incubated at 22 to $27^{\circ} \mathrm{C}$ for 7 days. The percentages of live nematodes were calculated as described above. The formula for the inhibition rate of proliferation was (live number of the control $\times$ live number of the treatment)/live number of the control $x$ 100. Each treatment was repeated three times.

Detection of Bacillus thuringiensis ICPs using sodium dodecyl sulfate polyacrylamide gel electrophoresis, liquid chromatography with MS, and spectral library query. Bacillus thuringiensis ICPs were separated on a sodium dodecyl sulfate polyacrylamide gel electrophoresis (SDS-PAGE) gel. Each target band in the SDS-PAGE gel and its corresponding position was recorded, and the bands were then cut out of the gel and individually placed in Eppendorf tubes. The bands were washed with $50 \mu \mathrm{l}$ of double-distilled $\mathrm{H}_{2} \mathrm{O}$ for 10 min twice. Then, the bands were repeatedly treated with $50 \mu \mathrm{l}$ of $50 \mathrm{mM} \mathrm{NH} \mathrm{HCO}_{3}$ /acetonitrile solution $(1: 1)$ at $37^{\circ} \mathrm{C}$ for $20 \mathrm{~min}$ until the blue dye faded. The gel bands were dehydrated with $50 \mu$ of acetonitrile until completely white. After vacuuming for $10 \mathrm{~min}, 20 \mu \mathrm{l}$ of $10 \mathrm{mM}$ DTT was supplemented to the gel band and treated at $56^{\circ} \mathrm{C}$ for $1 \mathrm{~h}$. The gel bands were then cooled to room temperature and dried. Next, $20 \mu \mathrm{l}$ of $55 \mathrm{mM}$ iodoacetamide (IAM) was added, and the tubes were placed in a darkroom for $45 \mathrm{~min}$. Then, the gel bands were dehydrated with $25 \mathrm{mM} \mathrm{NH}_{4} \mathrm{HCO}_{3}(2 \times 10 \mathrm{~min}), 25 \mathrm{mM} \mathrm{NH}_{4} \mathrm{HCO}_{3} / 50 \%$ acetonitrile solution $(2 \times 10 \mathrm{~min})$, and acetonitrile (10 $\mathrm{min})$ until completely white. After vacuuming for $10 \mathrm{~min}$, the gel was digested with 2 to $3 \mu \mathrm{l}$ of trypsin at $20 \mu \mathrm{g} / \mathrm{ml}$ and placed on ice for $30 \mathrm{~min}$. Then, $25 \mathrm{mM} \mathrm{NH}_{4} \mathrm{HCO}_{3}$ was added to the sample to a total volume of 10 to $15 \mu \mathrm{l}$ and incubated at $37^{\circ} \mathrm{C}$ overnight; $0.2 \%$ formic acid was added to stop the reaction.

Liquid chromatography (LC) with pulse Q collision-induced dissociation (PQD) tandem MS (LC-PQD-MS/MS) was performed at the Agricultural Ecology Institute, Fujian Agriculture and Forestry University, China. Briefly, high-performance liquid chromatography (HPLC) was first run with a Thermo Scientific Surveyor System (Thermo Fisher Scientific Inc.). The HPLC conditions were as follows: BioBasic C18 Column $(100 \times 0.18 \mathrm{~mm}$, particle size $=5 \mu \mathrm{m}) ; 10 \mu \mathrm{l}$ sample; mobile phase A, $0.1 \%$ formic acid in water, and phase B, $0.1 \%$ formic acid in acetonitrile; gradient condition $=5$ to $35 \% \mathrm{~B}$ for $20 \mathrm{~min}$ and 35 to $95 \%$ B for $2 \mathrm{~min}$; and flow rate of $2.5 \mu \mathrm{l} / \mathrm{min}$. Then, the MS/ MS was analyzed by an LTQ-XL linear ion trap mass spectrometer (Thermo Fisher Scientific Inc.). The MS conditions were as follows: mass spectrometer LTQ-XL, spray voltage $=3.5 \mathrm{kV}$, capillary temperature $=275^{\circ} \mathrm{C}$, sheath gas flow rate $=15$ arbitrary unit (arb), parent ion scan range $=400$ to $2,000 \mathrm{~m} / \mathrm{z}$, and isolation width $=2 \mathrm{Da}$. The secondary MS conditions were: AGC Target 1e4, 1 microscan, and collision energy $=35 \%$ collision induced dissociation (CID). Proteome Discoverer 1.2 Software (Thermo Fisher Scientific) was used to retrieve the relative quantitative analysis and database match. The Bacillus thuringiensis.fasta protein library was downloaded from https://www.ncbi.nlm.nih.gov/.

Detection of cry genes from $B$. thuringiensis BRC-XQ12 by PCR-RFLP. Total DNA was extracted from $B$. thuringiensis BRC-XQ12, and its cryl-cryl1 gene profile was identified by PCR-RFLP (Huang and Guan 2017; Huang et al. 2014; Kuo and Chak 1996; Song et al. 1998, 2003).

Cloning, sequence analysis, and localization of cry1Ea from $B$. thuringiensis BRC-XQ12. A pair of primers, $\operatorname{cry} 1 \mathrm{EF}\left(5^{\prime}\right.$ cgGGATCCATGGAGATAGTGAATAATCAGAATC-3') and cry1ER 
(5'-acgcGTCGACTTATTCCTCCATAAGAAGTAATTC-3'), designed using the sequence of $c r y l E a 6$ (GenInfo Identifier (gi) number 17979618), was used to amplify the crylEa gene from $B$. thuringiensis BRCXQ12 with high-fidelity vent DNA polymerase. The A tail was added to the PCR products by traditional PCR methods. Then, the PCR products were cloned into the pMD18-T vector to acquire the recombinant plasmid pMD-crylEa and were sequenced. The gene was submitted to the $B$. thuringiensis toxin nomenclature committee (http://www.lifesci.sussex.ac.uk/home/Neil_Crickmore/Bt/) and designated crylEall.

DNAMAN software was used to analyze the basic information of crylEal1. BLAST was used to search for sequence homology. ExPaSy (https://au.expasy.org) was used to predict the protein physicochemical properties, including amino acid composition, isoelectric point (pI), instability coefficient, and fat index.

The plasmid DNA and total DNA of BRC-XQ12 were extracted as described previously (Wu et al. 2004). Because the strain did not contain the plasmids, the localization of crylEall was performed with the following modifications: its plasmid DNA was used as the template for PCR as the negative control and the localization of the crylEall gene was directly detected by PCR using the chromosomal DNA of BRC-XQ12 recovered from its total DNA by a $0.7 \%$ agarose gel as the template.

Expression of Cry1Ea from B. thuringiensis BRC-XQ12 in E. coli. The pMD-crylEa harboring the crylEall gene and the expression plasmid pGEX-KG were double digested with BamHI and SalI. Then, they were ligated to obtain an E. coli containing the expression plasmid pGEX-crylEal1. This strain, E. coli BL21 (DE3)-pGEX-cry1Ea11, was registered with the China General Microbiological Culture Collection Center as number 7661. The E. coli strains containing pGEX-crylEal1 and pGEX-KG were cultured in LB and induced with $1 \mathrm{mM}$ isopropyl-thio-galactopyranoside (IPTG) at $16^{\circ} \mathrm{C}$ for $30 \mathrm{~h}$ to express GST-Cry1Ea1 1 and GST, respectively. The proteins were further purified with GST*bind resin.

Activity of GST-Cry1Ea11 against Bursaphelenchus xylophilus. A Bursaphelenchus xylophilus suspension was prepared and the assay was performed as described above. After 24 and $48 \mathrm{~h}$, the mortality, corrected mortality, and lethal concentration $50\left(\mathrm{LC}_{50}\right)$ were calculated. Purified GST and the elution buffer of GST-Cry1Ea were used as controls. The experiments were repeated three times.

Detection of the pathway of Bacillus thuringiensis Cry1Ea11 into Bursaphelenchus xylophilus with a CLSM. The experiments were performed as described previously, with some modifications (Yu et al. 2015; Zhang et al. 2012). Briefly, purified GST-Cry1Ea11 protein at $1 \mathrm{mg} / \mathrm{ml}$ was labeled with $3.5 \mu \mathrm{l}$ of NHS-Rhodamine $(10 \mathrm{mg} / \mathrm{ml})$ according to the manual procedure of the product (Thermo Scientific 46406), and was dialyzed with $20 \mathrm{mM} \mathrm{N}$-2-hydroxyethylpiperazine$N^{\prime}$-2-ethanesulfonic acid (HEPES) (pH 8.0). B. xylophilus was cultured and isolated as described above. Resorcinol $(1 \mathrm{mg} / \mathrm{ml})$ and nystatin $(100 \mu \mathrm{g} / \mathrm{ml})$ were added to the nematode to induce stylet pulsing frequency and to avoid the contaminations of microorganisms, respectively. Then, $100 \mu \mathrm{l}$ of labeled GST-Cry1Ea11 was mixed with 100 nematodes suspended in $100 \mu$ of sterile Milli-Q water in the wells of a 96-well plate. At 1 and $24 \mathrm{~h}$ postingestion (hpi), B. xylophilus was observed using a CLSM (Leica TCS SP8X DLS) at dual excitation laser wavelengths of 488 and $568 \mathrm{~nm}$ with two detectors (HyD1 at 500 to $550 \mathrm{~nm}$ and PMT 2 at 654 to $691 \mathrm{~nm}$ ) to determine the pathway of Cry1Ea11 into the nematode.

\section{RESULTS}

Screening of Bacillus thuringiensis strains active against Bursaphelenchus xylophilus. Of the 92 Bacillus thuringiensis strains tested, the corrected mortality of the fermentation broth of 8 , 13,14 , and 57 strains against Bursaphelenchus xylophilus was $>80,51$ to 80,31 to 50 , and 10 to $30 \%$, respectively. Bacillus thuringiensis strains BRC-CWS1, 140, BRC-SFR30, BRC-Bt2, BRC-XQ12, BRCZYR1, BRC-ZLL7, and BRC-ZY3 showed $>80 \%$ corrected mortality of Bursaphelenchus xylophilus. The nematodes were active without treatment with the Bacillus thuringiensis strains (Fig. 1A). After treatment with the B. thuringiensis strains for $12 \mathrm{~h}$, the nematodes began to show infection symptoms, including bradykinesia and body stiffness, swelling, and thickening, and they eventually died (Fig. 1B). BRC-XQ12 could even partially degrade part of the intestinal guts of the nematodes (Fig. 1C).

The above eight $B$. thuringiensis strains were selected for rescreening experiments. Using 30-fold diluted fermentation broth, the activities of the eight $B$. thuringiensis strains against the nematodes were in the order of BRC-ZY3 > 140 > BRC-ZLL7 > BRC-XQ12 > BRC-ZYR1 > BRCBt2 > BRC-CWS1 > BRC-SFR30, with corrected mortalities of 72.73, $63.33,57.14,56.31,54.54,52.94,50.00$, and $37.50 \%$, respectively.

Effects of $B$. thuringiensis ICPs on the mortality and reproduction of Bursaphelenchus xylophilus. It is convenient and fast to use Bacillus thuringiensis fermentation broth for nematicidal activity screening. According to previous articles, ICPs may be the major ingredients of $B$. thuringiensis fermentation broth active against nematodes. Thus, the ICPs were extracted from $B$. thuringiensis strains BRC-ZY3, 140, BRCZLL7, and BRC-XQ12 for bioassays. The results showed that the ICPs of the four strains killed the nematodes with varied virulence and different toxic speeds. The $\mathrm{LC}_{50}$ of B. thuringiensis 140 and BRC-XQ12 displayed a time-dependent decrease. The $\mathrm{LC}_{50}$ after 24-h treatments of B. thuringiensis BRC-ZLL7 and BRC-ZY3 slightly increased compared with that of the 12-h treatments, which may be related to the recovery of suspended animation of the nematodes. The results showed that BRC-XQ12 had the best effect, with an $\mathrm{LC}_{50}$ of $32.13 \mu \mathrm{g} / \mathrm{ml}$ after $48 \mathrm{~h}$ of treatment (Supplementary Fig. S1), indicating that its ICPs were responsible for the nematicidal activity.

The ICPs of BRC-XQ12 $(87 \mu \mathrm{g} / \mathrm{ml})$ inhibited the reproduction of Bursaphelenchus xylophilus. After treatment for 12,24 , and $36 \mathrm{~h}$, the inhibition rates of reproduction were 43.200, 44.286, and 47.709\%, respectively. BRC-XQ12 inhibited B. xylophilus reproduction up to $72.699 \%$ after treatment for $48 \mathrm{~h}$.

Detection of the ICPs profile of BRC-XQ12 using SDS-PAGE, LCPQD-MS/MS, and PCR-RFLP. To further investigate what kinds of ICPs have nematicidal activity, the ICPs profile of BRC-XQ12

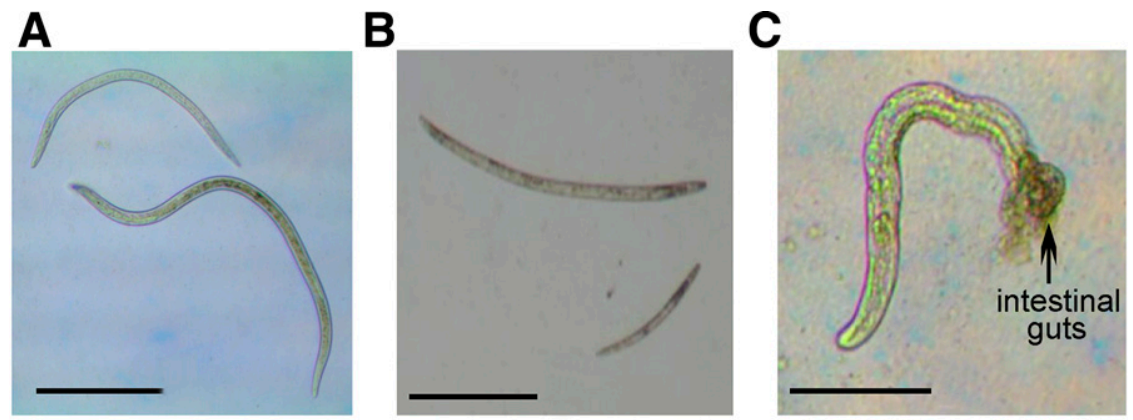

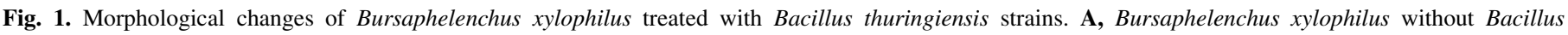

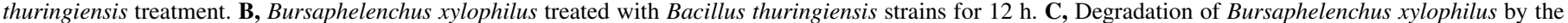
fermentation broth of Bacillus thuringiensis strain BRC-XQ12. Scale bars: $400 \mu \mathrm{m}$ (A and B) and $200 \mu \mathrm{m}(\mathrm{C})$. 
was first determined by SDS-PAGE and LC-PQD-MS/MS. The SDSPAGE results showed that the ICPs of BRC-XQ12 mainly ranged from 50 to $140 \mathrm{kDa}$, and the approximately $130-\mathrm{kDa}$ proteins were abundantly expressed (Fig. 2). Based on the mass and secondary spectra, the bands matched peptide sequences including RSENITPTL GINVVQGVGFIQPNNAEVLYR, IAEELPIRGGELYIDKIELILA DATFEEEYDLER, and NRGYDEAYESNSSVHASVYEEK, which corresponded to Cry1Ea6 (gi number 17,979,619), a 133.2-kDa protein with an pI value of 5.11 (Tables 1 and 2).

Three cry gene types of BRC-XQ12 (the cryl, cry 11 , and cry2 genes) were detected by PCR-RFLP using 10 pairs of universal primers (Fig. 3A). After treatment of the PCR products with the corresponding restriction endonucleases (Fig. 3B), the RFLP pattern showed products with sizes of approximately 1.10, 0.95, $0.75,0.65,0.50,0.22$, and $0.15 \mathrm{~kb}$ in lane 1 ; approximately 1.10 , $0.72,0.49,0.30$, and $0.25 \mathrm{~kb}$ in lane 2 ; approximately $0.57,0.44$, and $0.38 \mathrm{~kb}$ in lane 3 ; and approximately $0.79,0.30$, and $0.14 \mathrm{~kb}$ in lane 4. These were fit for the predicted RFLP sizes of $c r y 1 A a, c r y l C b$, cry $1 E a$, cry $1 I a$, and cry $2 A b$, suggesting that BRC-XQ12 contained these five kinds of cry genes (Fig. 3).

According to the above SDS-PAGE, LC-PQD-MS/MS, and PCRRFLP results, Cry1Ea is most likely responsible for the majority of the toxicity of BRC-XQ12 to B. xylophilus nematodes.

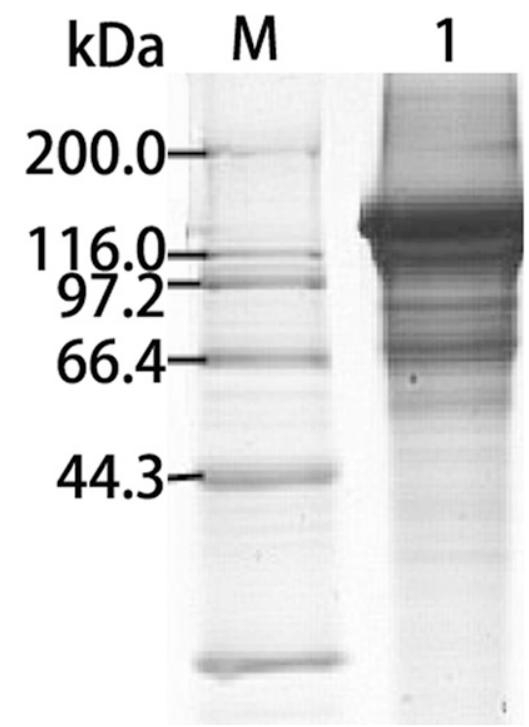

Fig. 2. Detection of insecticidal crystal proteins (ICPs) from Bacillus thuringiensis BRC-XQ12 using sodium dodecyl sulfate polyacrylamide gel electrophoresis. Lane M, TaKaRa Unstained Protein Molecular Weight Markers, and lane 1, ICPs from BRC-XQ12.
Cloning, sequence analysis, and localization of cry1Ea11 from BRC-XQ12. A correct recombinant JM109-pMD-crylEa containing the corresponding 3.5-kb cry $1 E a$ gene from BRC-XQ12 was obtained (Supplementary Fig. S2). After sequencing, the crylEa gene with a GenBank accession number JQ652456 was designated crylEall by the Bacillus thuringiensis Toxin Nomenclature Committee. The crylEall gene is 3,516 bp and encodes 1,171 amino acids, showing the highest similarity (99\%) with Cry1Ea6 (GenBank accession number AF202531.1). This is consistent with the results of LC-PQD-MS/MS.

The physicochemical properties of Cry1Ea11 were further predicted. The relative molecular weight of the Cry1Ea11 protein is $133.267 \mathrm{kDa}$, with a theoretical pI of 5.01, indicating that it is a weakly acidic protein. Of the 20 amino acids, the highest proportion of Cry1Ea11 is Leu (8.8\%), while Met is present at the lowest percentage $(0.7 \%)$ (Supplementary Fig. S3). It contains 165 acidic amino acids, 139 basic amino acids, 349 hydrophilic amino acids, and 518 hydrophobic amino acids (Supplementary Table S2). It has 165 negatively charged residues and 115 positively charged residues. The prediction of physicochemical properties provides a reference for subsequent protein expression and purification.

Because BRC-XQ12 did not contain the plasmids (Supplementary Fig. S4), its plasmid DNA was used as the template for crylEall PCR as the negative control. The localization of the crylEall gene was directly mapped to the chromosome of BRCXQ12 by PCR using the chromosomal DNA of BRC-XQ12 recovered from its total DNA by a $0.7 \%$ agarose gel as the template.

Expression and purification of Cry1Ea11 and its bioassay using Bursaphelenchus xylophilus. A recombinant E. coli BL21 (DE3)-pGEX-crylEal1 containing crylEal1 from pMD-crylEa was obtained (Supplementary Fig. S5). After IPTG induction, an approximately $160.0-\mathrm{kDa}$ protein, equal to the size of the fusion protein GST-Cry1Ea11 (133 kDa plus $26 \mathrm{kDa}$ ), was expressed (Fig. 4A). The fusion protein GST-Cry1Ea11 was further purified by GST*bind resin (Fig. 4B). GST protein, the 26-kDa negative control of the bioassay, was purified from E. coli BL21 (DE3)-pGEX$\mathrm{KG}$ using the same technique (Fig. 4C). Using GST protein as a negative control, the $\mathrm{LC}_{50}$ values of Cry1Ea11 after treatment for 24 and $48 \mathrm{~h}$ were 32.53 and $23.23 \mu \mathrm{g} / \mathrm{ml}$ with virulence equations $Y=32.15 X+1.38\left(R^{2}=0.9951\right)$ and $Y=34.29 X+3.16\left(R^{2}=\right.$ 0.9792), respectively (Supplementary Table S3; Supplementary Fig. S6).

NHS-rhodamine labeled 159 kDa GST-Cry1Ea11 entered into the PWN via the stylet in vitro. GST-Cry1Ea11 was labeled with NHS-rhodamine in order to determine whether it could be ingested by the PWN and to detect the pathways that it entered into the nematode. The nematode was observed by a laser confocal microscope. The results showed that the red fluorescence of the rhodamine was not seen in the nematode treated with NHS-rhodamine

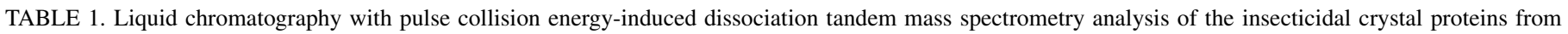
Bacillus thuringiensis strain BRC-XQ12a

\begin{tabular}{|c|c|c|c|c|c|c|c|c|}
\hline Accession number & $\operatorname{Cov}$ & PSM & Pep & AA & MW (kDa) & $\mathrm{pI}$ & Score & Description (B. thuringiensis) \\
\hline gi17979619 & 57.39 & 188 & 47 & 1,171 & 133.2 & 5.11 & $1,428.08$ & Cry032 \\
\hline gi37728716 & 46.74 & 151 & 38 & 1,181 & 133.3 & 5.10 & $1,225.92$ & Insecticidal crystal protein \\
\hline gi33339672 & 47.72 & 160 & 39 & 1,182 & 133.9 & 5.29 & $1,211.28$ & $\delta$-Endotoxin Cry1A \\
\hline gi23344760 & 55.06 & 145 & 39 & 1,177 & 133.1 & 5.14 & $1,132.98$ & Insecticidal crystal protein Cry $1 \mathrm{Ac}$ \\
\hline gi37781497 & 40.83 & 124 & 34 & 1,183 & 133.6 & 5.07 & $1,085.56$ & Cry1Aa \\
\hline gi142875 & 21.68 & 73 & 17 & 1,181 & 133.7 & 5.08 & 722.38 & $\delta$-Endotoxin \\
\hline gi1247711 & 17.81 & 63 & 16 & 1,179 & 133.3 & 5.15 & 632.11 & PS81RR1 \\
\hline gi259156864 & 23.55 & 49 & 17 & 1,227 & 138.9 & 5.22 & 427.89 & Cry1Be2 \\
\hline gi3360519 & 25.26 & 45 & 17 & 1,227 & 139.0 & 5.20 & 406.69 & Cry1Be1 $\delta$-endotoxin \\
\hline gi228911585 & 17.96 & 57 & 15 & 1,164 & 131.9 & 5.43 & 374.11 & Pesticidal crystal protein Cry1Ae \\
\hline gi45387401 & 20.85 & 34 & 15 & 1,170 & 133.2 & 5.40 & 369.66 & Crystal protein \\
\hline gi296087 & 10.58 & 44 & 9 & 1,172 & 132.9 & 5.21 & 314.00 & Crystal protein \\
\hline gi126566926 & 11.73 & 30 & 10 & 1,228 & 139.6 & 5.17 & 247.79 & Insecticidal protein Cry $1 \mathrm{Ba} 5$ \\
\hline
\end{tabular}

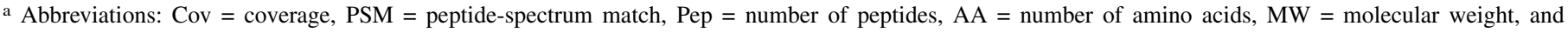
$\mathrm{pI}=$ calculated isoelectric point . 
labeled GST-Cry1Ea11 at $1 \mathrm{hpi}$ (Fig. 5A). At $24 \mathrm{hpi}$, the red fluorescence of rhodamine was detected in the stylet and esophageal lumen of the nematode (Fig. 5B). This showed that 159-kDa GST-Cry1Ea11 can enter into the PWN via the stylet in vitro.

\section{DISCUSSION}

Although there were early reports of PWD symptoms in 1905 in Nagasaki, Japan, it was not until 1971 that B. xylophilus was identified as the new species responsible for pine wilt (Kikuchi et al. 2009; Maehara 2008; Mallez et al. 2013). By 2009, PWD had spread from North America to Asia and Europe (Portugal) (Jones et al. 2013; Kikuchi et al. 2009). PWD has strong pathogenicity in that it spreads rapidly and causes host death quickly. It became an international danger to pine forest-like ecosystems, resulting in huge economic losses (Jung et al. 2010; Kusunoki 1987).

Bacillus thuringiensis ICPs can effectively control a variety of animal and plant-parasitic nematodes (Holterman et al. 2006; Hui et al. 2012; Iatsenko et al. 2014a; Li et al. 2008; Wang et al. 2014; Wu et al. 2015; Yu et al. 2015). In the 1960s, it was discovered that $B$. thuringiensis showed specific activity against nematodes (Ciordia and Blzzell 1961). In 1972, B. thuringiensis was found to play a role in the control of plant-parasitic nematodes: it not only inhibits egg hatching but also has nematicidal activity against the larvae (Bottjer et al. 1985). With further studies, people continued to find a variety of $B$. thuringiensis that killed nematodes, such as Caenorhabditis elegans, Pristionchus pacificus, Meloidogyne incognita, Panagrellus redivivus, Rotylenchulus reniformis, Aphelenchus avena, Heterodera glycines and Pratylenchus penetrans
(Griffitts et al. 2005; Iatsenko et al. 2014a,b; Kho et al. 2011; Rae et al. 2010; Wang et al. 2014; Wei et al. 2003; Yu et al. 2015; Zuckerman et al. 1993). B. thuringiensis can also effectively reduce the rate of root-knot caused by nematodes (Zuckerman et al. 1993). Extensive studies have been carried out to clone the related antinematode genes. The main $B$. thuringiensis biologically active substances against nematodes are 4.4- to $153.5-\mathrm{kDa}$ ICPs, whose corresponding genes belong to cry5B, cry6A, cry $14 A$, cry $21 A$, and cry55A (Guo et al. 2008; Wei et al. 2003). Recent studies showed that $B$. thuringiensis ICPs such as Cry5Ba3 can also kill Bursaphelenchus xylophilus (de Oliverira et al. 2004; Wang et al. 2012).

The current methods for characterization of Bacillus thuringiensis ICPs include bioassay, spore counting, HPLC methods, immunoassay, electrophoresis, MS, and genome mining. In this study, the main active component of BRC-XQ12, determined by combining bioassays, SDS-PAGE, and LC-PQD-MS/MS with PCR-RFLP, was identified as Cry1Ea11. The ICPs diversity detected by SDS-PAGE (Fig. 2) and the simplicity reported by LC-PQD-MS/MS (Table 1) were contradictory, in that $B$. thuringiensis ICPs are activated in insect alkaline guts by cutting off parts of their $\mathrm{N}$-terminal and $\mathrm{C}$-terminal amino acids into smaller proteins, which can be activated in vitro by $\mathrm{NaOH}$ or in vivo by alkali proteases. Thus, the small bands detected by SDS-PAGE were likely to be the activated smaller fragments from the $130-\mathrm{kDa}$ proteins. MS technology has been recognized as an important means of identification of peptides and proteins in proteomic analysis. In 2009, the peptides matching Cry19Ba, Cry40 ORF2, Cry27Aa, and Cry20Aa from a B. thuringiensis strain containing $75-$ to $30-\mathrm{kDa}$ ICPs were detected by nano-LC-electrospray ionization (ESI)-ion trap

TABLE 2. Insecticidal crystal proteins (ICPs) that highly matched the ICPs profile of Bacillus thuringiensis strain BRC-XQ12 detected by liquid chromatography with pulse collision energy-induced dissociation tandem mass spectrometry ${ }^{\mathrm{a}}$

\begin{tabular}{|c|c|c|c|c|c|c|c|c|c|c|}
\hline CI & Sequence coverage & Accession & Prob & Xcorr & $\Delta$ Score & m/z (Da) & $\mathrm{MH}+(\mathrm{Da})$ & $\Delta \mathrm{M}(\mathrm{ppm})$ & RT (min) & Ions \\
\hline High & $\begin{array}{l}\text { RSENITPTLGINV } \\
\text { VQGVGFIQPNNAEVLYR }\end{array}$ & $17,979,619$ & 115.93 & 7.81 & 0.41 & $1,100.88745$ & $3,300.6478$ & 573.65 & 59.68 & $46 / 116$ \\
\hline High & $\begin{array}{l}\text { IAEELPIRGGELYID } \\
\text { KIELILADATFEEEYDLER }\end{array}$ & $17,979,619$ & 300.00 & 7.10 & 0.55 & $1,322.95386$ & $3,966.84702$ & 206.66 & 62.46 & $40 / 132$ \\
\hline High & $\begin{array}{l}\text { IAEELPIRGGELYIDKIE } \\
\text { LILADATFEEEYDLER }\end{array}$ & $17,979,619$ & 105.78 & 6.94 & 0.53 & $1,323.13477$ & $3,967.38974$ & 343.43 & 62.36 & $42 / 132$ \\
\hline High & $\begin{array}{l}\text { IAEELPIRGGELYI } \\
\text { DKIELILADATFEEEYDLER }\end{array}$ & $17,979,619$ & 108.53 & 6.86 & 0.55 & $1,323.18616$ & $3,967.54392$ & 382.28 & 60.36 & $41 / 132$ \\
\hline
\end{tabular}

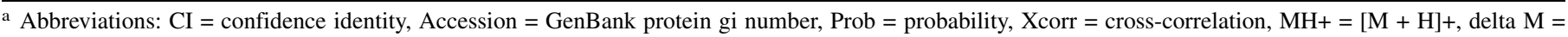
delta $\mathrm{M}, \mathrm{RT}=$ reaction time, and Ions = ions matched.
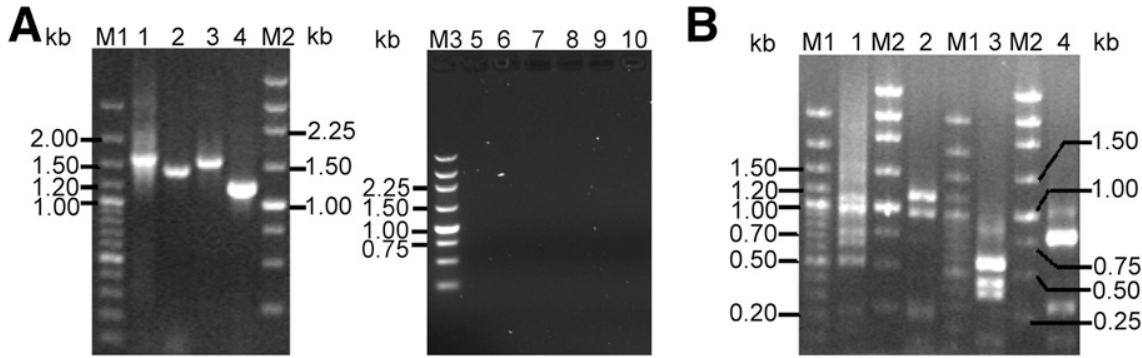

Fig. 3. Detection of $c r y$ genes from Bacillus thuringiensis strain BRC-XQ12 using polymerase chain reaction restriction fragment length polymorphism (PCR-RFLP). A, PCR products of the insecticidal crystal protein genes amplified from BRC-XQ12. Lane M1, GeneRuler 100-bp DNA Ladder Plus; lane M2, GeneRuler 250-bp DNA Ladder Plus; lane M3, TaKaRa 250-bp DNA ladder (Dye Plus); lanes 1 to 10, PCR products amplified with K5un2 (5'-AGGACCAGGATTTACAGGAGG-3')/K3un2 (5' GCTGTGACACGAAGGATATAGCCAC-3') (for cryl/cry7/cry9), K5un3 (5'-CAATGCGTACCTTACAATTGTTTAAGTAAT-3')/K3un3 (5'-CCTCCTGTAAATCC TGGTCCT-3') (for cryl/cry7/cry9), S5uni (5'-GCTGTCTACCATGATTCGCTTG-3')/S3uni(5'-CAGTGCAGTAACCTTCTCTTGC-3') (for cry1I), S5un2 (5'GGAAGAACTACTATTTGTGATGC-3')/S3un2 (5'-AATAGTTTGAATTACCGCGAGC-3') (for cry2), S5un3 (5' -ATGAATCCRAACAATCGAAG-3')/S3un3 (5' GGTCCATCTGTTGTTTCTG-3') (for cry3), S5un4 (5'-GTGTCAAGAGAACCAACAGTATG-3')/S3un4 (5'-ACTAAGTCTCCTCCTGTATGACCAG-3') (for cry4/ cry 10), cry5F (5'-AGTGATYATGAKATTGAAGAAG- $\left.{ }^{\prime}\right)$ /cry5R (5'-TTRTTRTTCATACTTGTATYGC- ${ }^{\prime}$ ) (for cry5), cry6F (5'-TATWATYTCWAARSAAGAATGGG$\left.3^{\prime}\right)$ /cry6R (5'-TKTAAMGAYGTTKYTCKAAGATT-3') (for cry6), cry8F (5'-ATGAGTCCAAATAATCAAAATG-3')/cry8R (5'-ATAACAWTCGTTTTTCATTTGG-3') (for $c r y 8$ ), and cry $11 \mathrm{~F}\left(5^{\prime}\right.$-GCATTAATAGCAGTAGCTCC-3')/cry11R (5'-GTATCTTCTAARAATGATCTATC- $3^{\prime}$ ) (for $c r y 11$ ), respectively. B, RFLP patterns of cry genes from BRC-XQ12. Lanes 1 to 4, PCR-amplified fragments of K5un2/K3un2, K5un3/K3un3, S5uni/S3uni, and S5un2/S3un2 digested with PstI/XbaI, EcoRI/PstI, Bsp119I/ BanI, and HincII/MspI, respectively; lane M1, GeneRuler 100-bp DNA Ladder Plus; and lane M2, GeneRuler 250-bp DNA Ladder Plus. 
(IT)-time of flight (TOF)-MS (Roh et al. 2009). In 2011, a simple method combining LC-ESI-MS with antifungal tests was applied to identify the compound produced by Bacillus subtilis CCMI 1051 that was against filamentous fungi as a lipopeptide (Caldeira et al. 2011). In 2012, at least 72 differentially expressed proteins related to metabolic changes during ICPs synthesis in B. thuringiensis YBT-1520 were detected by comparative proteomic analysis based on matrix-assisted laser desorption-ionization time-of-flight MS (Gong et al. 2012). By using PQD in this study, information from low-quality ion fragments can be provided, while the high selectivity of MS/MS spectra is helpful for retrieving a better match in the database and library, thus improving

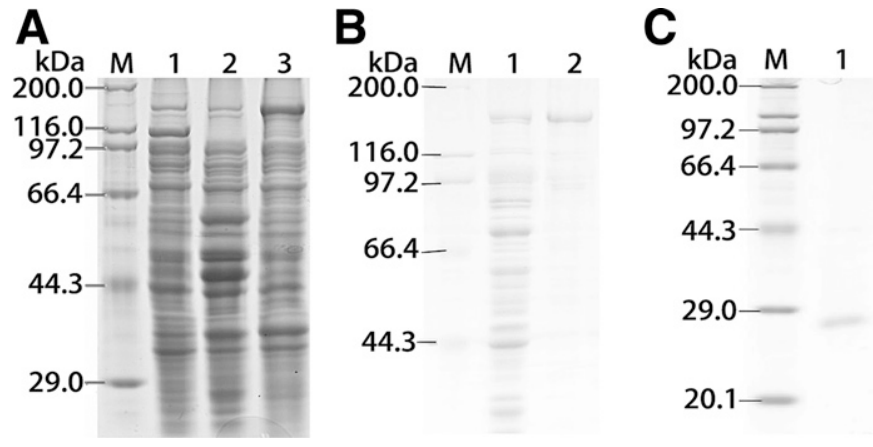

Fig. 4. Expression and purification of glutathione- $S$-transferase (GST)-Cry1Ea11 and GST. A, sodium dodecyl sulfate polyacrylamide gel electrophoresis (SDSPAGE) detection of the GST-Cry1Ea11 fusion protein expressed in Escherichia coli BL21 (DE3). Lanes 1 to 3, E. coli BL21 (DE3), E. coli BL21 (DE3)-pGEX$\mathrm{KG}$, and E. coli BL21 (DE3)-pGEX-cry1Ea11 induced by isopropyl-thiogalactopyranoside (IPTG), respectively; lane M, TaKaRa unstained protein molecular-weight markers. B, SDS-PAGE analysis of GST-Cry1Ea11 purified with GST*bind resin. Lane M, TaKaRa unstained protein molecular-weight markers; lane 1, supernatant of E. coli BL21 (DE3)-pGEX-cry1Eal1 induced with IPTG; and lane 2, fusion protein GST-Cry1Ea11 after GST-affinity column purification. C, SDS-PAGE analysis of GST purified by GST*bind resin. Lane M, TaKaRa unstained protein molecular-weight markers; and lane 1, GST protein expressed by E. coli BL21 (DE3)-pGEX-KG after GST-affinity column purification.
A

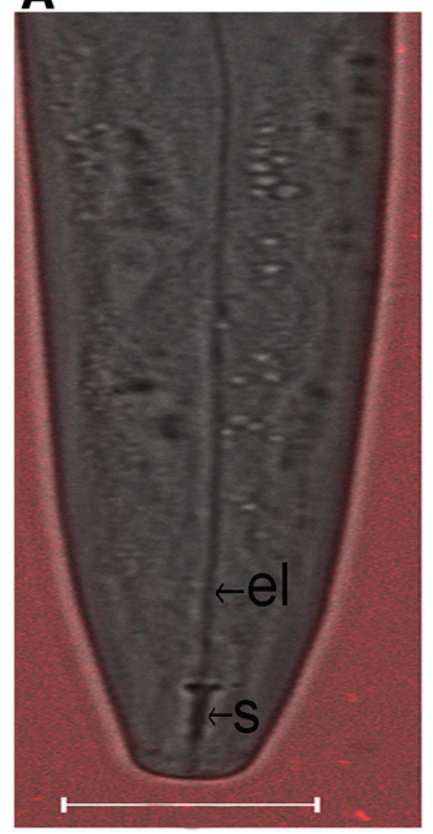

B

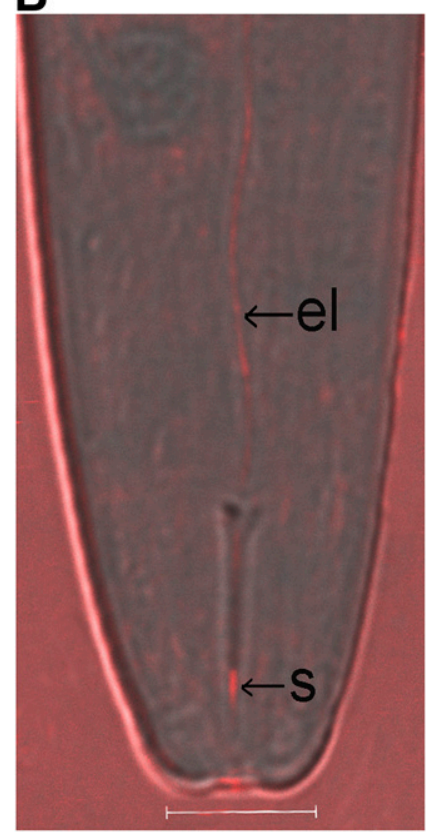

Fig. 5. Identification of the pathway of glutathione-S-transferase (GST)-Cry1Ea11 entering into Bursaphelenchus xylophilus. After B. xylophilus was incubated in NHS-Rhodamine-labeled GST-Cry1Ea11 for A, $1 \mathrm{~h}$ and $\mathbf{B}, 24 \mathrm{~h}$, the pathway of the nematode feeding the $159-\mathrm{kDa}$ GST-Cry1Ea11 was observed using confocal laserscanning microscopy and imaged using a merged image. Abbreviations: $\mathrm{s}=$ stylet and el = esophageal lumen. Scare bars of the images were $10 \mu \mathrm{m}(\mathrm{A})$ and $5 \mu \mathrm{m}(\mathrm{B})$. the reliability of the proof of structure. Therefore, MS technology is an important method for investigating the synthesis, properties, and other aspects of $B$. thuringiensis ICPs.

As a general description of strain BRC-XQ12, it is useful to perform plasmid profiling to check whether this strain carries plasmids and, if so, how many. This is important because the vast majority of cry genes are located on B. thuringiensis plasmids (Ye et al. 2012). In this study, however, the crylEall gene was localized on the chromosome of BRC-XQ12.

To the best of our knowledge, Cry1 have never been shown to have activity against plant-parasitic nematodes. Cry1Ea-like proteins were active against lepidoptera larvae of Spodoptera exigua (Visser et al. 1990), S. frugiperda (Rang et al. 2004), Manduca sexta (BarbozaCorona et al. 1998; Carmona et al. 2011), Pectinophora gossypiella (Tabashnik et al. 2000), and Anticarsia gemmatalis (Fiuza et al. 2013). This study found that Cry1Ea11 was toxic to Bursaphelenchus xylophilus, with an $\mathrm{LC}_{50}$ value of $23.23 \mu \mathrm{g} / \mathrm{ml}$, further dramatically broadening the spectrum of Bacillus thuringiensis ICPs.

Plant-parasitic nematodes use the stylet to feed, affecting the size and shape of the proteins ingested by them. To our knowledge, the size exclusion limit of the Bursaphelenchus xylophilus stylet remains unknown. However, the limit of other nematodes has been reported in the literatures. The nematode $H$. schachtii can only feed $28-\mathrm{kDa}$ proteins. The potato nematode Globodera rostochiensis can ingest 32-kDa proteins. The transgenic expression of 54-kDa Cry6A and truncated 79-kDa Cry5B in tomato roots significantly affected the reproductive ability of Meloidogyne incognita, indicating that it could feed at least 79-kDa proteins in vivo ( $\mathrm{Li}$ et al. 2007 , 2008). Further research showed that 45- to 140-kDa proteins can be taken by the root-knot nematode in vitro through the stylet (Zhang et al. 2012). Our study indicated that B. xylophilus could feed $159-\mathrm{kDa}$ GST-Cry1Ea11 protein via stylet in vitro.

Because plant-parasitic nematodes such as B. xylophilus live inside the plant body and rely on nutrients in plants, they are difficult to control, resulting in tremendous economic losses in many countries. Growing transgenic nematode-resistant plants is currently a recognized and feasible approach to control such nematodes. The crylEall gene obtained in this study will certainly provide a good foundation for breeding plants with antinematode genes. And it would be of considerable interest in the future researches to test whether Bacillus thuringiensis strain BRC-XQ12 and Cry1Ea11 are active against other nematodes to further broaden their application.

\section{ACKNOWLEDGMENTS}

This project was supported by the National Key R\&D Program of China (numbers 2017YFD0200400 and 2011AA10A203), the Project of FujianTaiwan Joint Center for Ecological Control of Crop Pests (number Minjiaoke [2013] 51), the National Natural Science Foundation of China (numbers 31672084 and 31201574), the Leading Talents of Fujian Province College (number k8012012a), and the Study-Abroad Scholarship of Fujian Province to T. P. Huang. We thank the teachers and the students of the Biopesticide Research Center for their help; senior editor M. Wubben and the journal referees for their constructive comments; colleagues X. Cheng, F. Zhang, Z. Yu, $X$. Fan, and S. Ma for their help in the identification of the pathway of Cry1Ea11 entering into Bursaphelenchus xylophilus; and W. Rao for the data processing of $\mathrm{LC}_{50}$ values.

\section{LITERATURE CITED}

Aikawa, T., Togashi, K., and Kosaka, H. 2003. Different developmental responses of virulent and avirulent isolates of the pinewood nematode, Bursaphelenchus xylophilus (Nematoda: Aphelenchoididae), to the insect vector, Monochamus alternatus (Coleoptera: Cerambycidae). Environ. Entomol. 32:96-102.

Akbulut, S., and Stamps, W. T. 2012. Insect vectors of the pinewood nematode: A review of the biology and ecology of Monochamus species. For. Pathol. 42:89-99.

Barboza-Corona, J. E., López-Meza, J. E., and Ibarra, J. E. 1998. Cloning and expression of the crylEa4 gene of Bacillus thuringiensis and the comparative toxicity of its gene product. World J. Microbiol. Biotechnol. 14:437-441. 
Batish, D. R., Singh, H. P., Kohli, S. K., and Kaur, S. 2008. Eucalyptus essential oil as a natural pesticide. For. Ecol. Manage. 256:2166-2174.

Beane, R. D., and Hobbs, N. T. 1983. The Baermann technique for estimating Protostrongylus infection in bighorn sheep: Effect of laboratory procedures. J. Wildl. Dis. 19:7-9.

Bottjer, K. P., Bone, L. W., and Gill, S. S. 1985. Nematoda: Susceptibility of the egg to Bacillus thuringiensis toxins. Exp. Parasitol. 60:239-244.

Bradford, M. M. 1976. A rapid and sensitive method for the quantitation of microgram quantities of protein utilizing the principle of protein-dye binding. Anal. Biochem. 72:248-254.

Bravo, A., Likitvivatanavong, S., Gill, S. S., and Soberon, M. 2011. Bacillus thuringiensis: A story of a successful bioinsecticide. Insect Biochem. Mol. Biol. 41:423-431

Caldeira, T., Arteiro, S., Coelho, V., and Roseiro, C. 2011. Combined use of LC-ESI-MS and antifungal tests for rapid identification of bioactive lipopeptides produced by Bacillus amyloliquefaciens CCMI 1051. Process Biochem. 46:1738-1746.

Carmona, D., Rodriguez-Almazan, C., Munoz-Garay, C., Portugal, L., Perez, C., de Maagd, R. A., Bakker, P., Soberon, M., and Bravo, A. 2011. Dominant negative phenotype of Bacillus thuringiensis Cry1Ab, Cry11Aa and Cry4Ba mutants suggest hetero-oligomer formation among different Cry toxins. PLoS One 6:e19952.

Chitwood, D. J. 2003. Research on plant-parasitic nematode biology conducted by the United States Department of Agriculture-Agricultural Research Service. Pest Manage. Sci. 59:748-753.

Chu, W. H., Dou, Q., Chu, H. L., Wang, H. H., Sung, C. K., and Wang, C. Y. 2015. Research advance on Esteya vermicola, a high potential biocontrol agent of pine wilt disease. Mycol. Prog. 14:115.

Ciordia, H., and Blzzell, W. E. 1961. A preliminary report on the effects of Bacillus thuringiensis var. thuringiensis Berliner on the development of the free-living stages of some cattle nematodes. J. Parasitol. 47: Sect. 2.

D’Addabbo, T., Laquale, S., Lovelli, S., Candido, V., and Avato, P. 2014. Biocide plants as a sustainable tool for the control of pests and pathogens in vegetable cropping systems. Ital. J. Agron. 9:137-145.

Dai, R., Su, X., Jin, X., Zhang, J., Guan, X., Chen, C., Shu, C., and Huang, T. 2016. Cloning, expression, purification, and insecticidal activity of a novel Cry1Na3 toxin from Bacillus thuringiensis BRC-ZYR2. J. Econ. Entomol. 109:1064-1070.

Deng, C., Peng, Q., Song, F., and Lereclus, D. 2014. Regulation of cry gene expression in Bacillus thuringiensis. Toxins (Basel) 6:2194-2209.

de Oliverira, E. J., Rabinocitch, L., Monnerat, R. G., Passos, L. K. J., and Zahner, V. 2004. Molecular characterization of Brevibacillus laterosporus and its potential use in biological control. Appl. Environ. Microbiol. 70: 6657-6664.

Fiuza, L. M., Knaak, N., da Silva, R. F., and Henriques, J. A. 2013. Receptors and lethal effect of Bacillus thuringiensis insecticidal crystal proteins to the Anticarsia gemmatalis (Lepidoptera, Noctuidae). ISRN Microbiol. 2013: Article ID 940284.

Gong, Y., Li, M., Xu, D., Wang, H., He, J., Wu, D., Chen, D., Qiu, N., Bao, Q., Sun, M., and Yu, Z. 2012. Comparative proteomic analysis revealed metabolic changes and the translational regulation of Cry protein synthesis in Bacillus thuringiensis. J. Proteomics 75:1235-1246.

Griffitts, J. S., Haslam, S. M., Yang, T. L., Garczynski, S. F., Mulloy, B., Morris, H., Cremer, P. S., Dell, A., Adang, M. J., and Aroian, R. V. 2005. Glycolipids as receptors for Bacillus thuringiensis crystal toxin. Science 307:922-925.

Guo, S., Liu, M., Peng, D., Ji, S., Wang, P., Yu, Z., and Sun, M. 2008. New strategy for isolating novel nematicidal crystal protein genes from Bacillus thuringiensis strain YBT-1518. Appl. Environ. Microbiol. 74:6997-7001.

Holterman, M., van der Wurff, A., van den Elsen, S., van Megen, H., Bongers, T., Holovachov, O., Bakker, J., and Helder, J. 2006. Phylum-wide analysis of SSU rDNA reveals deep phylogenetic relationships among nematodes and accelerated evolution toward crown clades. Mol. Biol. Evol. 23:1792-1800.

Huang, T., and Guan, X. 2017. PCR-RFLP screening of cry gene profiles in Bacillus thuringiensis and characterization of a novel cry $2 A b 8$ gene. Res. J. Biotechnol. 12:19-28.

Huang, T., Xiao, Y., Pan, J., Chen, Z., Li, L., Xu, L., Zhang, L., and Guan, X. 2014. Aerobic $\mathrm{Cr}(\mathrm{VI})$ reduction by an indigenous soil isolate Bacillus thuringiensis BRC-ZYR2. Pedosphere 24:652-661.

Hui, F., Scheib, U., Hu, Y., Sommer, R. J., Aroian, R. V., and Ghosh, P. 2012. Structure and glycolipid binding properties of the nematicidal protein Cry5B. Biochemistry 51:9911-9921.

Iatsenko, I., Boichenko, I., and Sommer, R. J. 2014a. Bacillus thuringiensis DB27 produces two novel protoxins, Cry21Fa1 and Cry21Ha1, which act synergistically against nematodes. Appl. Environ. Microbiol. 80: 3266-3275.

Iatsenko, I., Nikolov, A., and Sommer, R. J. 2014b. Identification of distinct Bacillus thuringiensis 4A4 nematicidal factors using the model nematodes Pristionchus pacificus and Caenorhabditis elegans. Toxins (Basel) 6:2050-2063.
Jones, J. T., Haegeman, A., Danchin, E. G. J., Gaur, H. S., Helder, J., Jones, M. G. K., Kikuchi, T., Manzanilla-Lopez, R., Palomares-Rius, J. E., Wesemael, W. M. L., and Perry, R. N. 2013. Top 10 plant-parasitic nematodes in molecular plant pathology. Mol. Plant Pathol. 14:946-961.

Jung, J., Han, H., Ryu, S. H., and Kim, W. 2010. Microsatellite variation in the pinewood nematode, Bursaphelenchus xylophilus (Steiner and Buhrer) Nickle in South Korea. Genes Genomics 32:151-158.

Kho, M. F., Bellier, A., Balasubramani, V., Hu, Y., Hsu, W. N., Nielsen-LeRoux, C., McGillivray, S. M., Nizet, V., and Aroian, R. V. 2011. The pore-forming protein Cry5B elicits the pathogenicity of Bacillus sp. against Caenorhabditis elegans. PLoS One 6:e29122.

Kikuchi, T., Aikawa, T., Oeda, Y., Karim, N., and Kanzaki, N. 2009. A rapid and precise diagnostic method for detecting the pinewood nematode Bursaphelenchus xylophilus by loop-mediated isothermal amplification. Phytopathology 99:1365-1369.

Kikuchi, T., Cotton, J. A., Dalzell, J. J., Hasegawa, K., Kanzaki, N., McVeigh, P., Takanashi, T., Tsai, I. J., Assefa, S. A., Cock, P. J. A., Otto, T. D., Hunt, M., Reid, A. J., Sanchez-Flores, A., Tsuchihara, K., Yokoi, T., Larsson, M. C., Miwa, J., Maule, A. G., Sahashi, N., Jones, J. T., and Berriman, M. 2011. Genomic insights into the origin of parasitism in the emerging plant pathogen Bursaphelenchus xylophilus. PLoS Pathog. 7:e1002219.

Kim, J., Seo, S. M., Lee, S. G., Shin, S. C., and Park, I. K. 2008. Nematicidal activity of plant essential oils and components from coriander (Coriandrum sativum), oriental sweetgum (Liquidambar orientalis), and valerian (Valeriana wallichii) essential oils against pine wood nematode (Bursaphelenchus xylophilus). J. Agric. Food Chem. 56:7316-7320.

Kotze, A., O’Grady, J., Gough, J., Pearson, R., Bagnall, N., Kemp, D., and Akhurst, R. 2005. Toxicity of Bacillus thuringiensis to parasitic and freeliving life-stages of nematode parasites of livestock. Int. J. Parasitol. 35: 1013-1022.

Kuo, W. S., and Chak, K. F. 1996. Identification of novel cry-type genes from Bacillus thuringiensis strains on the basis of restriction fragment length polymorphism of the PCR-amplified DNA. Appl. Environ. Microbiol. 62: 1369-1377.

Kusunoki, M. 1987. Symptom development of pine wilt disease histopathological observations with electron microscope. Ann. Phytopathol. Soc. Jpn. 53:622-629.

Li, X. Q., Tan, A., Voegtline, M., Bekele, S., Chen, C. S., and Aroian, R. V. 2008. Expression of Cry5B protein from Bacillus thuringiensis in plant roots confers resistance to root-knot nematode. Biol. Control 47:97-102.

Li, X. Q., Wei, J. Z., Tan, A., and Aroian, R. V. 2007. Resistance to root-knot nematode in tomato roots expressing a nematicidal Bacillus thuringiensis crystal protein. Plant Biotechnol. J. 5:455-464.

Maehara, N. 2008. Reduction of Bursaphelenchus xylophilus (Nematoda: Parasitaphelenchidae) population by inoculating Trichoderma spp. into pine wilt-killed trees. Biol. Control 44:61-66.

Mallez, S., Castagnone, C., Espada, M., Vieira, P., Eisenback, J. D., Mota, M., Guillemaud, T., and Castagnone-Sereno, P. 2013. First insights into the genetic diversity of the pinewood nematode in its native area using new polymorphic microsatellite loci. PLoS One 8:e59165.

Rae, R., Iatsenko, I., Witte, H., and Sommer, R. J. 2010. A subset of naturally isolated Bacillus strains show extreme virulence to the free-living nematodes Caenorhabditis elegans and Pristionchus pacificus. Environ. Microbiol. 12:3007-3021.

Rang, C., Bergvingson, D., Bohorova, N., Hoisington, D., and Frutos, R. 2004. Competition of Bacillus thuringiensis Cry1 toxins for midgut binding sites: A basis for the development and management of transgenic tropical maize resistant to several stemborers. Curr. Microbiol. 49:22-27.

Roh, Y., Liu, Q., Lee, W., Tao, X., Wang, Y., Shim, H., Choi, J., Seo, J., Ohba, M., Mizuk, E., and Je, Y. 2009. Bacillus thuringiensis serovar mogi (flagellar serotype $3 \mathrm{a} 3 \mathrm{~b} 3 \mathrm{~d}$ ), a novel sero group with a mosquitocidal activity. J. Invertebr. Pathol. 102:266-268

Sanahuja, G., Banakar, R., Twyman, R. M., Capell, T., and Christou, P. 2011. Bacillus thuringiensis: A century of research, development and commercial applications. Plant Biotechnol. J. 9:283-300.

Seo, S. M., Kim, J., Kim, E., Park, H. M., Kim, Y. J., and Park, I. K. 2010. Structure-activity relationship of aliphatic compounds for nematicidal activity against pine wood nematode (Bursaphelenchus xylophilus). J. Agric. Food Chem. 58:1823-1827.

Song, F. P., Zhang, J., Gu, A. X., Wu, Y., Han, L. L., He, K. L., Chen, Z. Y., Yao, J., Hu, Y. Q., Li, G. X., and Huang, D. F. 2003. Identification of cry1Itype genes from Bacillus thuringiensis strains and characterization of a novel cryll-type gene. Appl. Environ. Microbiol. 69:5207-5211.

Song, F. P., Zhang, J., Huang, D. F., Xie, T., Yang, Z., Dai, L., and Li, G. 1998. Establishment of PCR-RFLP identification system of cry genes from $\mathrm{Ba}$ cillus thuringiensis. Sci. Agric. Sin. 31:13-18.

Tabashnik, B. E., Liu, Y. B., de Maagd, R. A., and Dennehy, T. J. 2000. Crossresistance of pink bollworm (Pectinophora gossypiella) to Bacillus thuringiensis toxins. Appl. Environ. Microbiol. 66:4582-4584. 
Visser, B., Munsterman, E., Stoker, A., and Dirkse, W. 1990. A novel Bacillus thuringiensis gene encoding a Spodoptera exigua-specific crystal protein. J. Bacteriol. 172:6783-6788.

Wang, P. X., Zhang, C. Y., Guo, M. M., Guo, S. X., Zhu, Y. G., Zheng, J. S., Zhu, L., Ruan, L. F., Peng, D. H., and Sun, M. 2014. Complete genome sequence of Bacillus thuringiensis YBT-1518, a typical strain with high toxicity to nematodes. J. Biotechnol. 171:1-2.

Wang, Y. J., Mei, L., Wu, J., and Zhang, L. Q. 2012. Detection and characterisation of a Bacillus thuringiensis crystal protein with nematicidal activity against the pinewood nematode Bursaphelenchus xylophilus. Biocontrol Sci. Technol. 22:1143-1153.

Wei, J., Hale, K., Carta, L., Platzer, E., Wong, C., Fang, S., and Aroian, R. V. 2003. Bacillus thuringiensis crystal proteins that target nematodes. Proc. Natl. Acad. Sci. USA 100:2760-2765.

Wu, C. C., Hu, Y., Miller, M., Aroian, R. V., and Sailor, M. J. 2015. Protection and delivery of anthelmintic protein Cry5B to nematodes using mesoporous silicon particles. ACS Nano 9:6158-6167.

Wu, Z., Guo, W., Qiu, J., Huang, T., Li, X., and Guan, X. 2004. Cloning and localization of vip3A gene of Bacillus thuringiensis. Biotechnol. Lett. 26: 1425-1428.
Yang, Z. Q., Wang, X. Y., and Zhang, Y. N. 2014. Recent advances in biological control of important native and invasive forest pests in China. Biol. Control 68:117-128.

Ye, W., Zhu, L., Liu, Y., Crickmore, N., Peng, D., Ruan, L., and Sun, M. 2012. Mining new crystal protein genes from Bacillus thuringiensis on the basis of mixed plasmid-enriched genome sequencing and a computational pipeline. Appl. Environ. Microbiol. 78:4795-4801.

Yu, Z., Xiong, J., Zhou, Q., Luo, H., Hu, S., Xia, L., Sun, M., Li, L., and Yu, Z. 2015. The diverse nematicidal properties and biocontrol efficacy of Bacillus thuringiensis Cry6A against the root-knot nematode Meloidogyne hapla. J. Invertebr. Pathol. 125:73-80.

Zhang, F., Peng, D., Ye, X., Yu, Z., Hu, Z., Ruan, L., and Sun, M. 2012. In vitro uptake of $140 \mathrm{kDa}$ Bacillus thuringiensis nematicidal crystal proteins by the second stage juvenile of Meloidogyne hapla. PLoS One 7: e38534.

Zhao, L. L., Mota, M., Vieira, P., Butcher, R. A., and Sun, J. H. 2014. Interspecific communication between pinewood nematode, its insect vector, and associated microbes. Trends Parasitol. 30:299-308.

Zuckerman, B. M., Dicklow, M. B., and Acosta, N. 1993. A strain of Bacillus thuringiensis for the control of plant-parasitic nematodes. Biocontrol Sci. Technol. 3:41-46. 